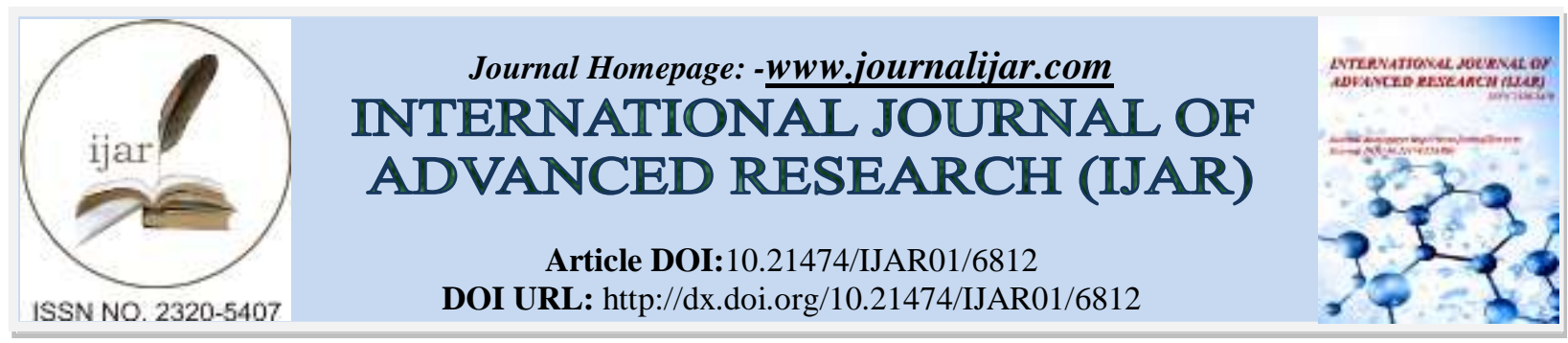

RESEARCH ARTICLE

\title{
COMPARATIVE EVALUATION OF SMEAR LAYER REMOVAL USING EDTA, PASSIVE ULTRASONIC IRRIGATION \& DIODE LASER: A SCANNING ELECTRON MICROSCOPIC STUDY.
}

\author{
Paromita Mazumdar ${ }^{1}$ and Abiskrita Das ${ }^{2}$. \\ 1. Professor and H.O.D, Department of Conservative Dentistry \& Endodontics, Guru Nanak Institute of \\ Dental Sciences and Research, 157/F Nilgunj Road, Panihati, Kolkata-700114. \\ 2. Post Graduate student, Department of Conservative Dentistry \& Endodontics, Guru Nanak, Institute of \\ Dental Sciences and Research, 157/F, Nilgunj Road, Panihati, Kolkata-700114.
}

\section{Manuscript Info}

Manuscript History

Received: 22 January 2018

Final Accepted: 24 February 2018

Published: March 2018

\section{Keywords:-}

Diode laser; ethylenediaminetetraacetic acid, root canal irrigants, passive ultrasonic irrigation.

\section{Abstract}

Aim: To evaluate the efficacy of smear layer removal from the root canals using EDTA, passive ultrasonic irrigation, diode laser during endodontic therapy.

Materials and method: 30 extracted human mandibular first premolar teeth were selected. Access cavity preparation was done. Working length was determined Instrumentation was initiated with ISO hand files no. $15 \mathrm{k}$ file upto $20 \mathrm{k}$ file followed by protaper rotary files upto size F3. $2 \mathrm{ml} \mathrm{NaOcl}$ was used as an irrigant after every instrumentation followed by a rinse with $3 \mathrm{ml}$ of distilled water. Samples were divided into three groups (group I-EDTA+PUI, group II- EDTA+DIODE LASER, group III- EDTA+DIODE LASER+ PUI). Samples were divided longitudinally. Scanning electron microscope examination of canals was done for remaining

smear layer at apical third levels.

Result: Combination of diode laser and ultrasonics with EDTA had the least smear layer scores.

Conclusion: The combination of diode laser and passive ultrasonic irrigation showed the best result in removal of smear layer.

Copy Right, IJAR, 2018,. All rights reserved.

\section{Introduction:-}

The fundamental aim of non surgical endodontic treatment is to shape and clean the root canals as thoroughly as possible to eliminate debris and microorganisms and achieve three dimensional fluid tight seal. [1] A complete debridement of the root canal is essential to achieve an effective disinfection and a three-dimensional obturation for a favorable long-term prognosis. However, after instrumentation of the root canals, an amorphous, irregular layer is formed on the root canal walls known as smear layer.[2]

Irrigation is defined as washing out a body cavity or wound with water and medicated fluid. Endodontic Irrigation is the process of delivery of endodontic irrigants within the root canal. Irrigation is complementary to instrumentation in facilitating removal of bacteria, debris and necrotic tissue, especially from areas of the root canal that remain unprepared by mechanical instruments.[3] 
Effective irrigation depends on various irrigants and irrigation devices and techniques. Various solutions used for removing the smear layer include phosphoric acid, citric acid, maleic acid, ethylenediaminetetraacetic acid (EDTA), and MTAD (a mixture of tetracycline isomer, an acid, and a detergent). Sodium hypochlorite ( $\mathrm{NaOCl}), 1-5.25 \%$ concentration as an irrigant is widely used in root canal treatment as it is bactericidal and has the ability to dissolve organic tissues but non effective in removing the smear layer. [4] Traditional needle irrigation has been proved to be insufficient for a complete cleaning of the complex anatomy of root canal system (especially the lateral canals, isthmuses and the apical third), therefore endeavors are being made to develop new irrigants and irrigating devices to improve the root canal disinfection in everyday endodontic practice.[5]

Various chemicals, ultrasonics, and lasers, in combination or alone, have been evaluated for the removal of the smear layer with varying results. Passive ultrasonic irrigation has been used nowadays for removal of the smear layer. The ultrasonic irrigating system works on the principle of sonic activation of files to produce hydrodynamic intracanal fluid agitation.[6]

Lasers have also been used to remove the smear layer such as argon laser, neodymium-doped yttrium aluminum garnet, $\mathrm{CO} 2$ laser, erbium-doped yttrium aluminum garnet and diode. Currently, a final irrigation sequence with a chelating agent EDTA and $\mathrm{NaOCl}$ is being used to remove the inorganic and organic components of the smear layer.[4]

This study is designed to evaluate the efficacy of smear layer removal from the root canals using EDTA, passive ultrasonic irrigation, diode laser during endodontic therapy.

\section{Materials And Method:-}

30 extracted human mandibular first premolar teeth were selected noncarious mandibular premolars were taken for the study. Inclusion criteria included single-rooted teeth with straight, patent roots, and fully formed apices, extracted for periodontal or orthodontic reasons.

\section{Sample preparation:-}

The teeth were stored in $10 \%$ formalin solution till they were used for the study. The root surfaces were cleaned. After standardization, the working length of specimens was determined by deducting $1 \mathrm{~mm}$ from the length of the \#10/\#15 K-file after it was passively placed in the canal until the tip of the instrument visibly penetrated the apical foramen. Access cavity preparation was done. Working length was determined. Instrumentation was initiated with ISO hand files no. $15 \mathrm{k}$ file upto $20 \mathrm{k}$ file followed by protaper rotary files upto size $\mathrm{F} 3$. $2 \mathrm{ml} \mathrm{NaOcl}$ was used as an irrigant after every instrumentation followed by a rinse with $3 \mathrm{ml}$ of distilled water.

Samples were then divided into three groups:-

Group I: EDTA + PASSIVE ULTRASONIC IRRIGATION

Group II: EDTA+ DIODE LASER

Group II: EDTA +PASSIVE ULTRASONIC IRRIGATION + DIODE LASER

GROUP I: The root canals were irrigated with a final flush of $1 \mathrm{ml} 17 \%$ EDTA with passive ultrasonic irrigation for $1 \mathrm{~min} .15 \mathrm{no}, 21 \mathrm{~mm}$ irrisaf ultrasonic file placed $1 \mathrm{~mm}$ short of working length and followed by $3 \mathrm{ml}$ of NaOcl

GROUP II:- The root canals were irrigated with $1 \mathrm{ml}$ of $17 \%$ EDTA then diode laser application was done. The fibre optic tip was introduced into the root canals upto the working length. The laser was then activated and gently withdrawn from the root canals and then reintroduced to the apex for a total cycle of 20 seconds.

GROUP III:- The root canals were irrigated with a final flush of 1ml EDTA with passive ultrasonic irrigation for 1 min followed by diode laser

\section{Sample Preparation For Scanning Electron Microscopy:-}

The teeth samples were grooved longitudinally on the external surface with a diamond disc with low speed without penetration into the root canals and then split into two halves with a chisel. Specimen was dehydrated with a layer of ethanol for $24 \mathrm{hrs}$. After dehydration, samples were placed in a vacuum chamber and sputter coated with a $30 \mathrm{~nm}$ gold layer. The dentinal wall of the root canals was examined at apical thirds at a magnification of $\times 2000$ for the 
presence or absence of smear layer and patency of dentinal tubules. Photomicrographs of the root canals were taken at apical level for scoring individually in a calibrated single-blind manner according to the rating system developed by Gutmann $e t$ al.

Gutmann rating system for remaining smear layer scores:-

\begin{tabular}{|l|l|}
\hline SCORE & CRITERIA \\
\hline $\mathbf{1}$ & $\begin{array}{l}\text { Little or no smear layer; covering }<25 \% \text { of the specimen; most } \\
\text { tubules were visible and patent, or almost complete laser melting }\end{array}$ \\
\hline $\mathbf{2}$ & $\begin{array}{l}\text { Little to moderate or patchy mounts of smear layer; covering } \\
25-50 \% \text { of the specimen; many tubules visible and patent, or } \\
\text { laser melting }\end{array}$ \\
\hline $\mathbf{3}$ & $\begin{array}{l}\text { Moderate amounts of scattered of aggregated smear layer; } \\
\text { covering 50-75\% of the specimen; minimal to no tubule } \\
\text { visibility or patency, or scattered laser melting }\end{array}$ \\
\hline $\mathbf{4}$ & $\begin{array}{l}\text { Heavy smear layer covering }>75 \% \text { of the specimen; no tubule } \\
\text { orifices were visible or patent; or no visible laser melting }\end{array}$ \\
\hline
\end{tabular}

Data were subjected to statistical analysis and analyzed using one-way anova analysis of variance using the SAS.

\section{Result:-}

The scores at apical third for all three groups was calculated as the mean score and standard deviation. At the apical third level, Group III followed by Group II had the least smear layer scores with no significant difference them. This was followed by Group I. Group III showed the least smear layer scores in the apical third region. Group I showed the highest smear layer scores in the apical third region. At the apical third, the cleaning efficacy of the combination of laser and passive ultrasonic irrigation was better when compared to the laser and passive ultrasonic irrigation individually.

Remaining smear layer scores:-

\begin{tabular}{|l|l|l|l|l|l|}
\hline GROUPS & 1 & 2 & 3 & 4 & Total \\
& $<25 \%$ & $25-50 \%$ & $50-75 \%$ & $75 \%$ & 1 \\
\hline A (PUI) & 0 & 4 & 5 & $0 \%$ & 10 \\
& $0.00 \%$ & $40.0 \%$ & $60.0 \%$ & 0 & $100.0 \%$ \\
\hline B (Laser) & 1 & $60.0 \%$ & $30.0 \%$ & $0 \%$ & 10 \\
& $0 \%$ & 4 & 0 & 0 & $100.0 \%$ \\
\hline C & 6 & $40.0 \%$ & $0 \%$ & $0 \%$ & $100.0 \%$ \\
(PUI & $60.0 \%$ & & & & \\
\hline
\end{tabular}

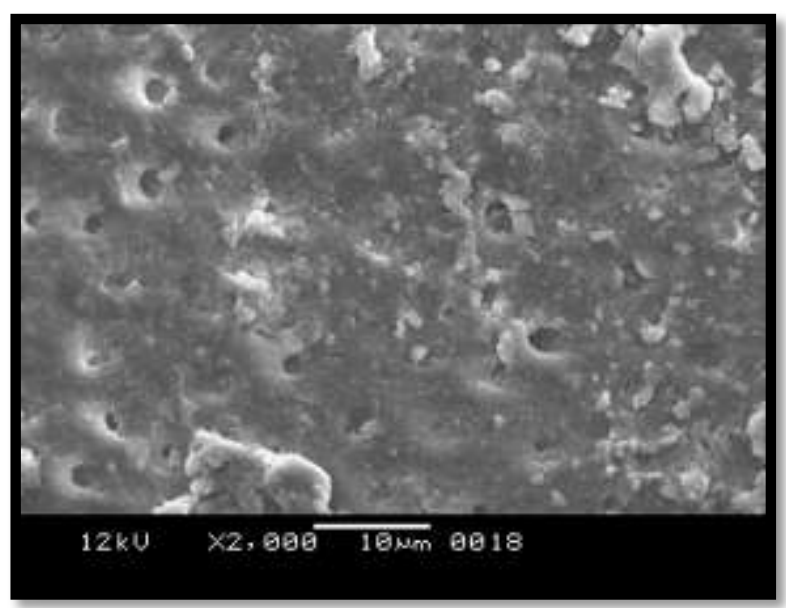

EDTA+ PASSIVE

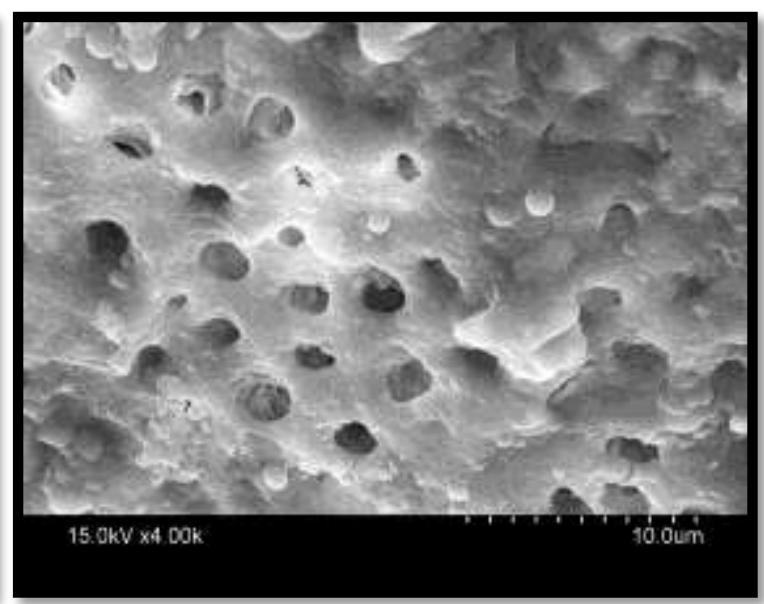

EDTA+DIOD 


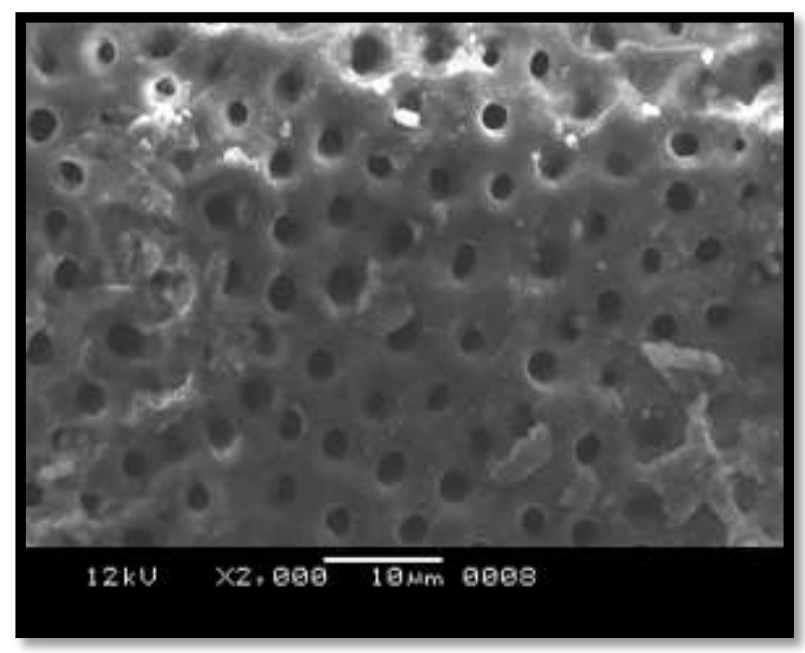

EDTA+PASSIVE ULTRASONIC +

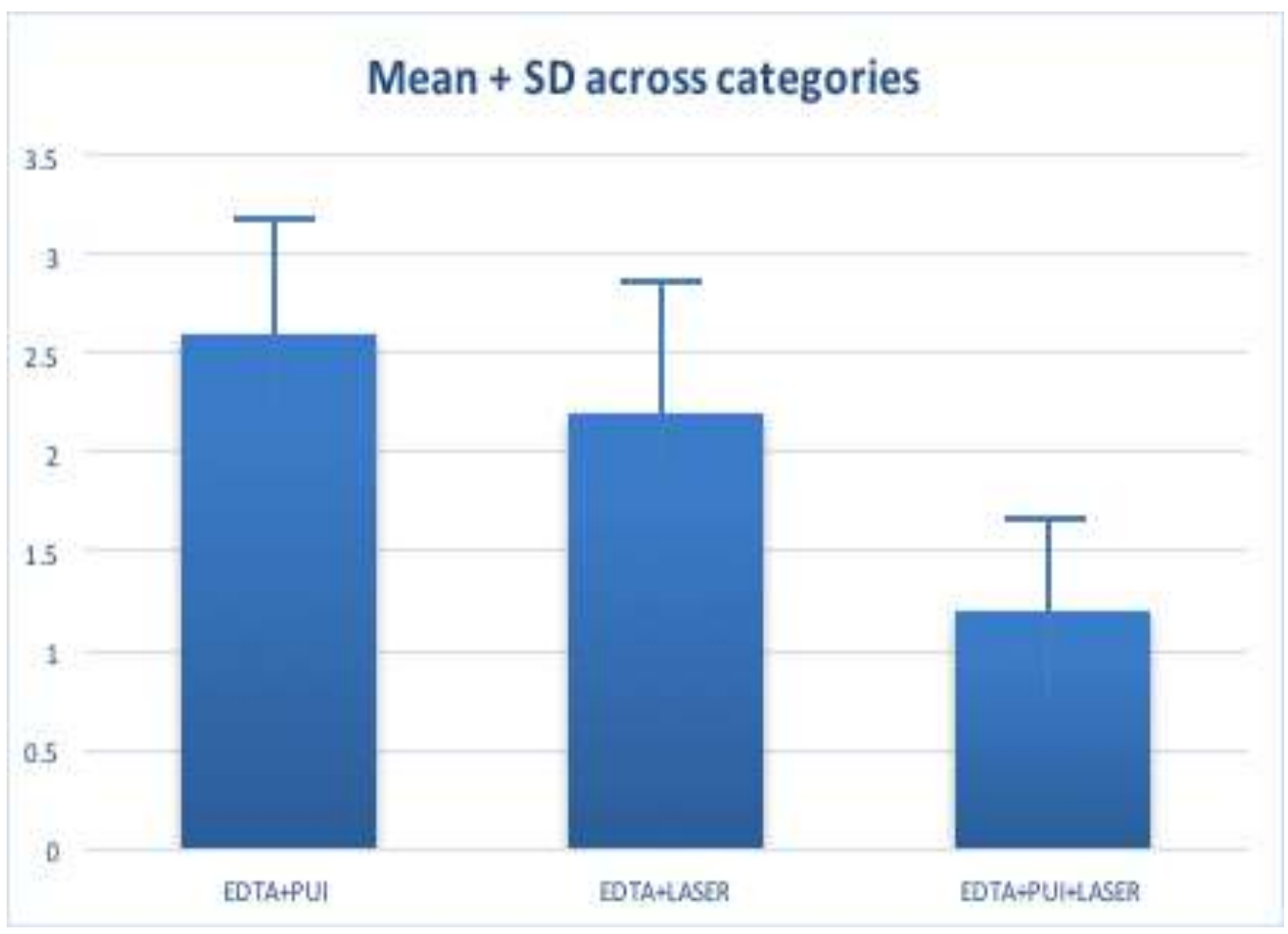

1. Among all the 3 categories EDTA+PUI+LASER showed the minimum SEM score, average being 1.2. Statistically the score is significantly low compared to other 2 categories. P value is as low as lower than 0.0001 .

2. When we compare individually, SEM score of EDTA+PUI+LASER V/S EDTA+LASER is low and is also statistically significant. $\mathrm{P}$ value is lower than 0.0001 .

3. When we compare individually, SEM score of EDTA+PUI+LASER V/S EDTA+PUI is low and is also statistically significant.P value is lower than 0.0001 .

\begin{tabular}{|l|l|l|l|}
\hline & EDTA + PUI & EDTA+LASER & EDTA=PULASER \\
\hline MEAN & 2.6 & 2.2 & 1.2 \\
\hline STANDAR DEVIATION & 0.5 & 0.6 & 0.4 \\
\hline
\end{tabular}




\section{Discussion:-}

The aim of this study was to evaluate the effect of three different irrigating protocols in removing the smear layer at the apical third of the dentinal wall. During shaping of the canals, debris and a smear layer are created. Irrigating solutions may be inefficient in removing the smear layer completely, especially from the apical thirds of root canals. [7]

EDTA reacts with the calcium ions in dentine and forms soluble calcium chelates. EDTA decalcify dentin to a depth of $20-30 \mu \mathrm{m}$ in $5 \mathrm{~min}$. The decalcifying process is self-limiting, because the chelator is used up. EDTA is most commonly used as a $17 \%$ neutralized solution (disodium EDTA, $\mathrm{pH} 7$ ). The optimal working time of EDTA is 15 minutes, after which time no more chelating action can be expected. [8]

Recently, agitation of irrigating solutions with passive ultrasonic irrigation and laser devices has become popular. By using ultrasonic the temperature of the irrigants increased causing reduced surface tension along with increased vibrational energy.[9]

The conventional needle irrigation technique does not provide complete cleaning of the root canal system. The effectiveness and safety of irrigation depends on the means of delivery. Traditionally, irrigation has been performed with a plastic syringe and an open-ended needle into the canal space. [10]

Passive ultrasonic irrigation (PUI) uses an ultrasonically activated file to energize the irrigant in the canal and to create acoustic streaming. Ultrasonic devices were first introduced in endodontics by Richman. Ultrasonic energy produces higher frequencies $(25-30 \mathrm{kHz})$ than sonic energy but low amplitudes. They operate in transverse vibration.[11] PUI was first described by Weller et al. The term passive does not adequately describe the process, since it is in fact active. The term passive relates to non cutting action of ultrasonically activated file. [12] The active streaming of the irrigant, increases its potential to contact a greater surface area of the canal wall. After the canal has been shaped, a small file or a smooth wire is introduced at the centre of the canal, as far as the apical region. Canal is then filled with irrigating solution, and ultrasonically oscillating file activates the irrigant. [11] Ultrasound is sound energy with frequency above 25 -30 KHZ. Instruments driven by a piezoelectric element near $30 \mathrm{kHz}$ exhibit a pattern of approximately three wavelengths, or six nodes and antinodes spaced approximately 5 $\mathrm{mm}$ apart. The oscillation amplitude of the tip of such instruments is on the order of 10-100 $\mu \mathrm{m}$ in the direction of oscillation, there is also an oscillation perpendicular to the main oscillation direction with a relative amplitude of approximately 10\%. [12] When a small file (size 10-20) is placed freely in the center of the canal following preparation and ultrasonic activation is given, the ultrasonic energy passage through irrigating solution and exerts its acoustic streaming effect. [5]

Acoustic streaming can be defined as a rapid movement of fluid in a circular or vortex-like motion around a vibrating file. The oscillatory part of the acoustic streaming makes the flow oscillate forward and backward together with the file. In doing so, the fluid exerts an alternating pressure and shear stress on the root canal wall.[13] The addition of ultrasonics to EDTA increased the smear layer removing efficacy of EDTA by enhancing its penetration into the narrow apical regions of the root canals.[4]

Laser-assisted irrigation (LAI) technique using diode lasers, used for irrigation. Divito et al used this technique with a radial fiber tip at a subablative power setting which, they demonstrated, results in significantly better removal of the smear layer as compared to saline water irrigation. The diode laser was able to remove the smear layer from the root canal surfaces, however, most of the dentinal tubules were obliterated with smear plugs. [14] The apical third had lesser smear layer as there is narrower diameter of the canal in the apical region resulting in a closer approximation of the laser tip to the root canal walls and thus melting and evaporating the smear layer easily.[15] The results of the present study showed laser diode with the combination of PUI with EDTA to be superior to PUI with EDTA and laser diode with EDTA alone in removing the smear layer. With diode laser and EDTA, the smear layer was removed from the root canals, the dentinal tubules were obliterated at apical level. [15] The results were similar to the study of Faria et al who found absence of smear layer and partially obliterated dentinal tubules after application of $980 \mathrm{~nm}$ diode laser on root canals irrigated with $1 \% \mathrm{NaOCl}$ plus 17\% EDTA. Laser diode showed comparatively better result than PUI in terms of removal of smear layer.

In this study, the apical third of the canals were least influenced by the ultrasonic irrigation. Ultrasonics is not able to effectively get through the apical vapor lock in the apical $3 \mathrm{~mm}$ of the canal. It has been shown that once an 
ultrasonically activated tip leaves the irrigant and enters the apical vapor lock, acoustic microstreaming and/or cavitation becomes physically impossible which is not the case with the apical negative pressure irrigation technique. This is because acoustic microstreaming or cavitation is only possible in fluids/ liquids, not in gases. [16] The oscillation of the tips of ultrasonic instruments were decreased by constraining it in the root canal. Because the amplitude of the oscillation is largest at the instrument's tip, any attenuation affects the apical part most significantly where the diameter of the canal was smallest.[12] The combined use of ultrasonic and EDTA followed by a combination of diode laser and EDTA performed better than EDTA, diode, and ultrasonics used alone. Suggesting that the incorporation of ultrasonics and diode laser with EDTA might prove beneficial in increasing the ability of EDTA to remove the smear layer. The diode laser used alone proved to be effective than PUI in the apical. [4]

The combined use of ultrasonic and EDTA followed by a combination of diode and EDTA performed better than EDTA, diode, and ultrasonics used alone in removing smear layer suggesting that the incorporation of ultrasonics and diode laser with EDTA might prove beneficial in increasing the ability of EDTA to remove the smear layer by enhancing its interaction with the root canal walls particularly in the apical regions.

\section{Conclusion:-}

Within the limitations of the current study, all the tested groups were able to remove the smear layer from the prepared root canals to different degrees. When used alone diode laser performed significantly better than passive ultrasonic irrigation. The combination of diode laser and passive ultrasonic irrigation showed the best result in removal of smear layer. Diode laser could be a good addition to the armamentarium used for smear layer removal and could increase the success rate of endodontic therapy.

\section{References:-}

1. Sabir Muliyar et al(2014), Microleakage in Endodontics, Journal of International Oral Health 2014; 6(6):99-104

2. Larz S et al(2002), Rationale and efficacy of root canal medicaments and root filling materials with emphasis on treatment outcome, Endodontic Topics 2002, 2, 35-58

3. Jack in et al(2006), Intracanal Medicame nts Revisited, New Zealand Endodontic Journal Vol 34 July 2006

4. Khalid Amin et al (2016), Effect of diode laser and ultrasonics with and without ethylenediaminetetraacetic acid on smear layer removal from the root canals: A scanning electron microscope study, Journal of Conservative Dentistry, Sep-Oct 2016, Vol 19, Issue

5. Sanghamitra Suman, et al (2017), A Comparative Evaluation of Smear Layer Removal Using Apical Negative Pressure (EndoVac), Sonic Irrigation (EndoActivator) and Er:YAG laser -An In Vitro SEM Study, J Clin Exp Dent. 2017;9(8):e981-7.

6. Gianluca Plotino, et al (2016), New Technologies to Improve Root Canal Disinfection Brazilian Dental Journal (2016) 27(1): 3-8

7. A. M Darrag, (2014), Effectiveness of different final irrigation solutions on smear layer removal in intraradicular dentin, Tanta Dental Journal 11 (2014) 93e99

8. Zahed Mohammadi et al, (2013), Ethylenediaminetetraacetic acid in endodontics, European Journal of Dentistry, Vol 7,Supplement 1, Sept 2013

9. Laurence J.Walsh et al (2017), Activation of Alkaline Irrigation Fluids in Endodontics, Materials 2017, 10, 1214

10. Markus Haapasalo et al(2010), Irrigation in Endodontics, Dent Clin N Am 54 (2010) 291-312

11. L. W. M. van der Sluis et al (2007), Passive ultrasonic irrigation of the root canal: a review of the literature, International Endodontic Journal, 40, 415-426, 2007

12. Sandra Mozo et al (2012), Review of ultrasonic irrigation in endodontics: increasing action of irrigating solutions, Med Oral Patol Oral Cir Bucal. 2012 May 1;17 (3):e512-6.

13. Jeffrey S. Marshall et al (2015), Acoustic streaming, fluid mixing, and particle transport by a Gaussian ultrasound beam in a cylindrical container, Phys. Fluids 27, 103601 (2015)

14. L. B. AYRANCI et al, (2016) Effectiveness of Laser-Assisted Irrigation and Passive Ultrasonic Irrigation Techniques on Smear Layer Removal in Middle and Apical Thirds, SCANNING VOL. 38, 2 (2016)

15. Ivana Parcina Amizic,et al (2016) Influence of Laser Activated Irrigation with Erbium Lasers on Bond Strength of Inidividually Formed Fiber Reinforced Composite Posts to Root Canal Dentin, Acta stomatol Croat. 2016;50(4):321328.

16. Nishi Singh et al (2014), A comparative evaluation of different irrigation activation systems on smear layer removal from root canal: An in-vitro scanning electron microscope study, Journal of conservative dentistry Year : 2014, volume : 17, Issue : 2,Page : 159-163 